\title{
A Comprehensive Approach towards Enhancing the Interface for Wedding Website Hosting
}

\author{
Mudit Mathur \\ School Of Information Technology, \\ VIT University, \\ Vellore TamilNadu \\ Chandan Kalra \\ School Of Information Technology, \\ VIT University, \\ Vellore TamilNadu
}

\author{
Ritik Arora \\ School of Information Technology, \\ VIT University, \\ Vellore TamilNadu \\ Sree Dharinya S \\ Assistant Professor \\ School of Information Technology \\ VIT University
}

\begin{abstract}
In today's world the inception of an idea is what it takes to bring about changes and make improvements and if that idea is incepted properly into the people then you have accomplished success. So we are bringing one such idea about wedding website hosting. There is hardly anybody who doesn't know about internet. When companies are running their business online, people are in contact with their dear and near with social networking websites, there is a need of wedding websites also, with which people can share their most precious memories with whomever and whenever they want. People around the world are busy in their life but they still want to attend the precious moments like weddings of their loved ones. So to keep them updated and sharing each and every memory of this unique occasion, an innovative idea like wedding website hosting will bring more happiness to them.
\end{abstract}

\section{General Terms}

Php, html, security, mobile, application, creative, technical, security

\section{Keywords}

Packages, themes, architecture, wedding, website, hosting, interface.

\section{INTRODUCTION}

The web based "Wedding Website Hosting" project is an attempt to implement the basic concepts of website hosting and wedding website concepts and by using these concepts together, it allows the customer to have their wedding website ready in a matter of minutes. The basic idea behind this concept is that any user around the world can create their wedding website and they can provide all the basic information or any information they want to share with their friends and relatives. They just need to have moments like those collected in pictures and words to express them and rest work will be done by the website. They will provide pictures and words and we will give them a wedding website.

The basic working of the website will be such that the main page will have a login box with information about the website. The login box will have a "Sign In" option for the users who are already a member of the website and another option of "Guest Login". When the user will click on guest login, he will be redirected to the page of the website containing complete information and step by step tutorial to create their wedding website. There will be different themes and packages link provided on this page. This website will have keynotes of the features that the website will provide for the users.

\section{FEATURES}

\subsection{Main Features}

The main features of the wedding website can be viewed by the users. The main features will include the user friendly interface, the step by step tutorial, sample templates, availability of multiple themes for the user to choose, subscription to the newsletters, updates about the latest features added, 24X7 customer helpline. They can forward their problems through email also. One of the most important features that everybody wants in their wedding website is the domain name. For certain members depending upon the packages to which the users are subscribing, they will be provided a unique domain name that they want. Customers do not want the name of the hosting website in their wedding website domain name. So customers can avail this feature also if they want their website to be special.

There will be certain features like SMS notifications and Social networking connectivity like facebook. They can import their contacts or groups or friend list from their email accounts and send direct invitation to them via email.

They can send instant invitation by availing SMS facility also but for that, they will have to pay separately.

\subsection{Packages and Themes}

The customers will be provided with different packages. Each package will contain certain features and with the increase in price of the subscription of the package, the features will also increase. The basic package will be valid for 1 year with a limitation on uploading of data with limited features on the website. There will be visa/debit/net banking feature available for the payment of the subscription. Customers will be able to avail monthly as well as yearly packages. Customers will be able to unsubscribe the package at any moment of time. For each action of customer, he will be notified with an email.

Users will also be able to choose any of the themes that he wishes to use on his/her website. He will have a choice of changing the theme at any moment of time. The different themes will showcase the preview of their wedding website. It 
will give them the basic idea of how their website will look like when they upload the information to the website.

These packages and themes will be prepared in such a way that user can use them as per his/her requirements. The main idea here is to give less emphasis on technicality and to give preference to creativity. We are focusing on a creative approach to get maximum benefit out of it.

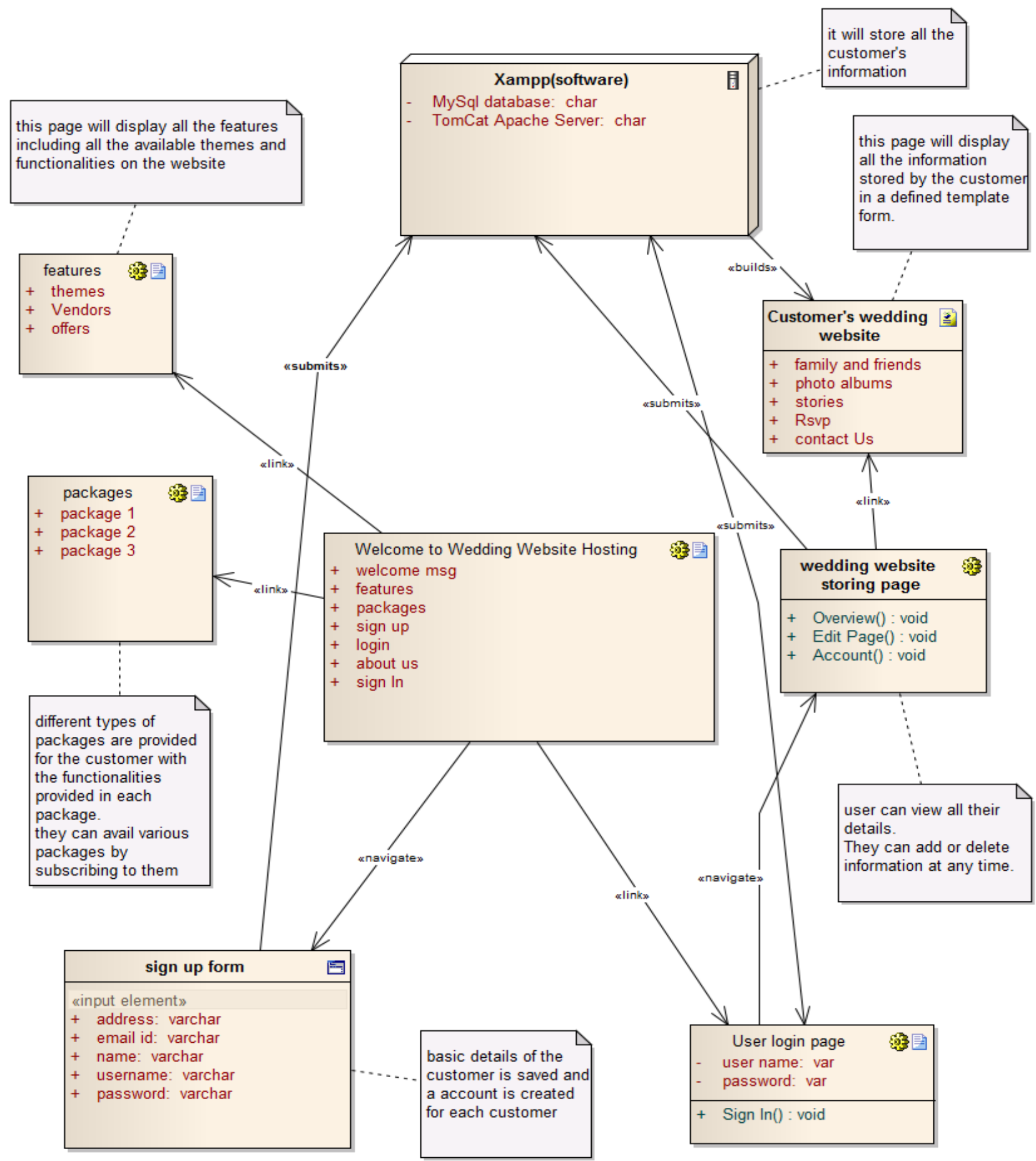

Fig. 1: Architecture Specification of the Wedding website hosting

\section{OVERALL ARCHITECTURE}

The architecture of the website (Fig.1) is in such a way that the user will find it very compulsive and user friendly. User will not need to be an expert or anything. The whole designing will be in such a fashion that even novice users can use it to make their dream wedding website.

The main website will have all the necessary information that a user wants to know. The connectivity to the other pages will 
be standard. We will use HTML5 [1], CSS [2], PHP [3] technologies in developing this website. All the requirements of the user will be kept in consideration while providing them the interface to provide information. We will ask for feedback also so that we will come to know about the areas where we need more improvement. The main website will be having all the necessary links to features, packages, signup form, and login page.

Once the user will create a unique account for his/her wedding website, he will be displayed the features that he can use to provide the information or to upload the information into his website's database so that the information can be viewed on his website. All the data will be stored in the database. User can make changes to the database at any time whenever he/she wishes.

\section{WEBSITE LAYOUT}

The layout of the user's website will be such that, there will be a user friendly backend interface from where user will operate all the operations of the website or we can say that there will be a user friendly control panel for user's website. This control panel will have different options for the user to go through the website and to work properly. First tab on the control panel will provide all the basic details of the user's account, subscription, and packages etc. The details about the database storage capacity, space used, new offers, discounts etc. will also be displayed here. The next tab in this control panel will be about the user's details. This will display user's personal information like name, address, phone number, email id, bride's name, groom's name, wedding date etc.

The next tab will control all the operations of the website. It will show all the features that user wish to display on his wedding website and the information that he wants to store in those features. If he wishes to hide any of these features then user needs to disable it from here. If he wishes to upload information as well as images or URL depending on the feature, then he needs to upload it here. There will be a direct link also available here for the user to view the changes he made to his website by clicking on the "view website" button.

User can change the theme of his website directly from this control panel also. He will be provided with a tutorial as well as customer care service also, if he gets stuck somewhere. Certain features like providing the whole website as album in form of a soft copy etc. can be kept for future enhancements.

\section{SECURITY ASPECTS}

One of the most important concerns while implementing such idea at large scale is security. There should be proper security to protect user's data, identity and to prevent the server from breaking down. For such an aspect of Secure and Highperformance, Web Server System for Shared Hosting Service is used [4].

\section{OBSERVATION AND STATISTICS}

According to an online website [5] whose goal is to provide the most comprehensive and up-to-date resource for bridal statistics and consumer wedding costs and majority of this information comes from online websites such as Bridal Association of America, TheKnot, Data Monitor, The wedding Report etc. In 2012, the average cost of a U.S. wedding is $\$ 26 \mathrm{~K}-\$ 27 \mathrm{~K}$ (honeymoon not included). While this number varies by region, season, day of the week and style, it accurately portrays what most planning couples ultimately spend for this big day. This dollar amount is a logical indication and baseline for an average 2012 wedding budget.

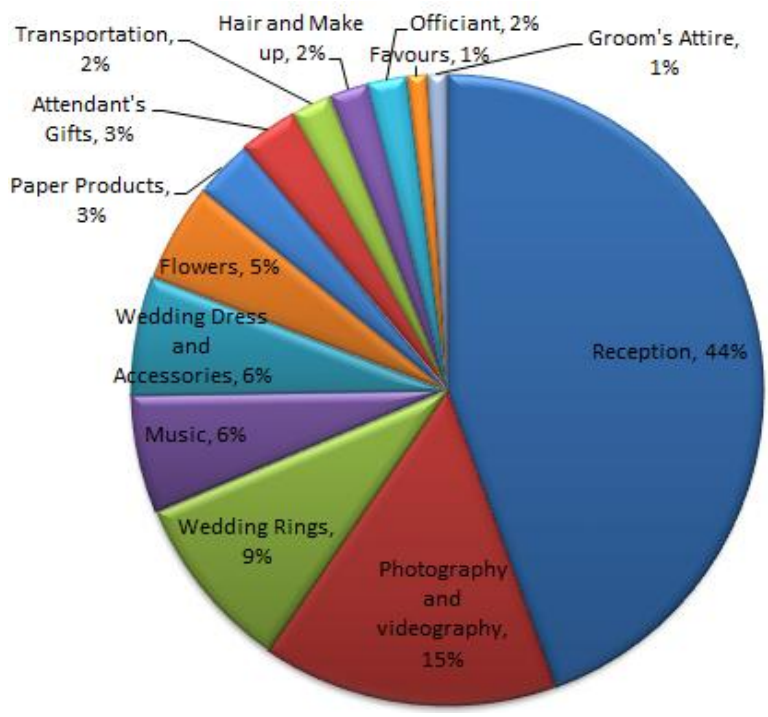

Fig. 2: Category wise wedding budget distribution

It is clearly visible from Fig.2 that people are spending majority of their money on reception to have quality time. So why should they lag behind in terms of technology? When they are spending so much on each and every aspect of their wedding, then they won't hesitate to spend few more to have their own personal wedding website.

Fig. 2 can be used as a reference to the average percentage expenditure on each and every aspect of wedding. With such budget, everyone would love to have their own wedding website. This can actually bring a huge crowd to the wedding websites.

According to a research company [6] that tracks and forecasts number of weddings, spending and consumer trends for the wedding industry, the number of weddings during the period of 1945 to 2010 in millions were as follows :-

\section{Weddings 1945-2010 (In Millions.)}

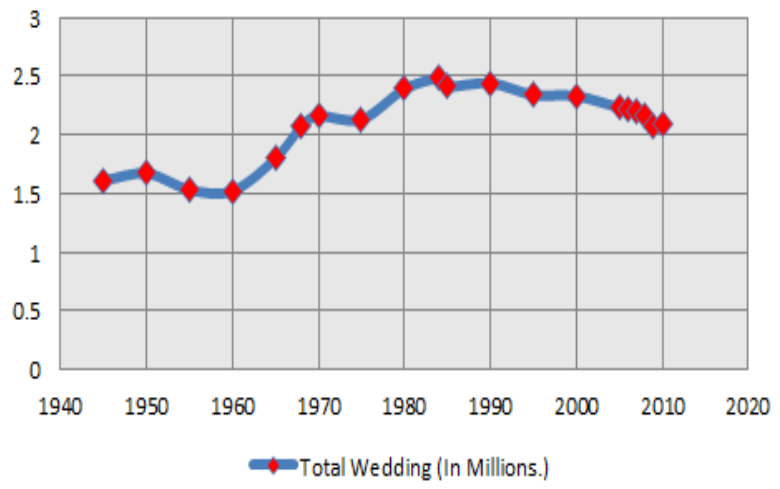

Fig. 3: Total Weddings from 1945-2010 in millions in USA 
Table 1.Tabular representation of statistics of total weddings from 1945-2010 in Fig. 3

\begin{tabular}{|c|c|}
\hline Year & Total Wedding (In Millions.) \\
\hline 1945 & 1.61 \\
\hline 1950 & 1.67 \\
\hline 1955 & 1.53 \\
\hline 1960 & 1.52 \\
\hline 1965 & 1.80 \\
\hline 1968 & 2.07 \\
\hline 1970 & 2.16 \\
\hline 1975 & 2.13 \\
\hline 1980 & 2.39 \\
\hline 1984 & 2.48 \\
\hline 1985 & 2.41 \\
\hline 1990 & 2.44 \\
\hline 1995 & 2.34 \\
\hline 2000 & 2.33 \\
\hline 2005 & 2.23 \\
\hline 2006 & 2.21 \\
\hline 2007 & 2.20 \\
\hline 2008 & 2.16 \\
\hline 2009 & 2.08 \\
\hline 2010 & 2.10 \\
\hline
\end{tabular}

According to Fig. 3 and Table 1, it is clearly visible from the statistics of last 65 years that wedding industry is never going to decline. So even if the concept of wedding website hosting is new to the people at this time, we can expect that when they will be aware of this idea then it will become an entire separate industry where everybody would provide the best they can provide to the customers.

There exists few websites like http://ewedding.com [7], http://momentville.com [8] etc. with such idea but still there is no boom in this area because what people need is awareness and right publicity and a directed approach with a unique approach of focusing on creativity and use of right technology.

\section{CONCLUSION}

In the end we can conclude that wedding website hosting industry is a new field where if the idea is planned and implemented properly, can lead to a huge traffic. If people are made aware about it, then this can be a great success. As we said already in the beginning, inception is what matters. If the idea is properly incepted to the right people at the right time in a proper way, then there is no stopping to the success because in this case, wedding website hosting is one such unique way of connecting traditional weddings or marriage with technology. In future the concept of wedding website hosting can be extended to mobile and handheld equipment like android mobiles and tablets with the help of their respective mobile agents. Another future scope of this idea can be extended to occasions apart from weddings. If this industry receives the expected crowd then the developers can definitely extend their expertise from just wedding to other occasions where people want to have their personal website dedicated to the occasion.

This idea will bring about a dynamic change in the thinking of people. Till now there was a mentality that only rich can own website but now a common person can also have their own website and can fulfill their dreams.

\section{REFERENCES}

[1] HTML: Hyper Text Markup Language 5. http://en.wikipedia.org/wiki/HTML5

[2] CSS: Cascading style sheets. www.w3schools.com/css/

[3] PHP: hypertext Preprocessor http://www.php.net/.

[4] Daisuke Hara and Yasuichi Nakayama Secure and High Performance Web Server System for Shared Hosting Service

[5] http://weddingstats.org :An online wedding statistics provider

[6] www.weddingreport.com : An online research company founded by Shane McMurray

[7] http://ewedding.com, an online wedding hosting website

[8] http://momentville.com, an online wedding hosting website

[9] S. Goodwin and R. Vidgen. Content, content, everywhere...time to stop and think? The process of Web content management, IEE Computing \& Control Engineering Journal, Vol.13, No.2, pp. 66-70, 2002.

[10] D. Hara, R. Ozaki, K. Hyoudou, and Y. Nakayama. Design and Implementation of A Web Server for A Hosting Service, Proc. the 9th IASTED International Conference on Internet and Multimedia Systems and Applications, pp. 69-74, 2005.

[11] "UDDI Technical White Paper," OASIS UDDI, Tech. Rep., September 2000. [Online]. Available: http://www.uddi.org

[12] H. He, "What is Service-Oriented Architecture?" O'Reilly webservices.xml.com, 2003. [Online]. Available: xml.com/pub/a/ws/2003/09/30/soa.html $\mathrm{http} / / /$ webservices.

[13] L.M. Spangenberg, Timeless Traditions: A Couple's Guide to Wedding Customs Around the World. New York, NY: Universe Publishing, 2001.

[14] D. Warner, Diane Warner's Contemporary Guide to Wedding Ceremonies. Franklin Lakes, NJ: New Page Books, 2006.

[15] M. Cooper, J. Foote, A. Girgensohn, and L. Wilcox, "Temporal event clustering for digital photo collections," in Proc. 11th ACM Int. Conf. Multimedia (MM'03), 2003, pp. 364-373

[16] R. C. Gonzalez and R. E.Woods, Digital Image Processing, 2nd ed. Upper Saddle River, NJ: PrenticeHall, 2001. 


\section{ABOUT THE AUTHORS}

MUDIT MATHUR is pursuing his B.Tech in information technology from Vellore institute of technology Vellore, TamilNadu India. He is currently in his final year. His research interests are in the field of networking, software development life cycle and object oriented analysis and design.

RITIK ARORA is pursuing his B.Tech in information technology from Vellore institute of technology Vellore, TamilNadu India. $\mathrm{He}$ is currently in his final year. His research interests are Algorithms, web designing, software engineering.
CHANDAN KALRA is pursuing his B.tech in information technology from Vellore institute of technology Vellore, TamilNadu India. He is currently in his final year. His research interests are in the field of cloud computing.

SREE DHARINYA $\mathbf{S}$ is working as Assistant Professor in VIT University in the dept. of SITE with an experience of ten years. Her area of interest is software engineering and object oriented analysis and design. 